\title{
Does Catheter Ablation Lower the Long-Term Risk of Stroke and Mortality in Patients with Atrial Fibrillation? A Concise Review of the Current State of Knowledge
}

\author{
Robert Ryad ${ }^{1}$, Suhail M. Saad-Omer ${ }^{2}$, Farah Khan ${ }^{3}$, Therese Limbana $^{3}$, Nusrat Jahan ${ }^{4}$ \\ 1. Internal Medicine, California Institute of Behavioural Neurosciences and Psychology, Brentwood, USA 2. Medicine, \\ California Institute of Behavioural Neurosciences and Psychology, Fairfield, USA 3. Psychiatry, California Institute of \\ Behavioural Neurosciences and Psychology, Fairfield, USA 4. Internal Medicine, California Institute of Behavioural \\ Neurosciences and Psychology, Fairfield, USA
}

Corresponding author: Robert Ryad, robert.ryad.97@gmail.com

\begin{abstract}
Atrial fibrillation (AF) is the most common cardiac arrhythmia worldwide and carries a significant risk of morbidity and mortality. Multiple trials have highlighted the benefit of catheter ablation over medical therapy in restoring sinus rhythm and improving quality of life. Whether it reduces long-term risk of stroke and mortality is still unclear.
\end{abstract}

We performed a literature search using the PubMed database to review the current state of knowledge regarding the long-term outcomes of stroke and mortality in ablated patients compared to patients who receive medical therapy. Our review mainly consisted of recent randomized controlled trials and large observational studies.

Results from large observational studies show that catheter ablation significantly reduces the risk of stroke in high-risk patients and mortality compared to medical therapy. However, randomized controlled trials have only demonstrated a mortality benefit in patients with comorbid systolic heart failure. In patients with paroxysmal AF, ablation therapy significantly limits the progression to persistent AF and has a higher efficacy in restoring sinus rhythm. Maintenance of sinus rhythm is the most important factor associated with lower long term risk of stroke and mortality.

Large randomized controlled trials similar to the Catheter Ablation Versus Anti-arrhythmic Drug Therapy for Atrial Fibrillation (CABANA) trial are still needed to clarify whether catheter ablation is superior over medical therapy in improving the long-term outcomes of stroke and mortality.

\section{Received 07/17/2020 \\ Review began 07/29/2020 \\ Review ended 07/30/2020 \\ Published 08/12/2020 \\ () Copyright 2020 \\ Ryad et al. This is an open access article distributed under the terms of the Creative Commons Attribution License CC-BY 4.0., which permits unrestricted use, distribution, and reproduction in any medium, provided the original author and source are credited.}

Categories: Cardiology, Internal Medicine

Keywords: atrial fibrillation, catheter ablation, mortality, stroke

\section{Introduction And Background}

Atrial fibrillation (AF) is the most common cardiac arrhythmia and is regarded as a future epidemic among aging populations with an estimated worldwide prevalence of $0.51 \%$ and consistently increasing incidence rates [1]. It imposes a five-fold increased risk of stroke and a two-fold increased risk of dementia and mortality [2,3]. From another perspective, atrial fibrillation receives an annual share of 26 billion dollars of the US healthcare expenditure, and the increasing rate of incidence predicts further cost burden in the future [2].

Treatment for atrial fibrillation is either pharmacological or non-pharmacological. As for pharmacological therapy, the Atrial Fibrillation Follow-up Investigation of Rhythm Management (AFFIRM) trial was set to settle the long-standing debate of rate control vs. rhythm control and concluded that there was no superiority to either strategy. However, the investigators reported more adverse effects in the rhythm control arm, which could have potentially masked the results that failed to show any benefit (mortality or stroke risk reduction) for maintaining sinus rhythm [4].

Catheter ablation is the non-pharmacological form of therapy that has gained popularity in recent years. Randomized controlled trials have shown that in comparison to anti-arrhythmic drugs, catheter ablation is more successful in reducing arrhythmia recurrence and improving quality of life [5-8]. However, data comparing the long-term outcomes of stroke and mortality is still insufficient [9]. In this article, we review the current evidence to highlight whether there is any long-term benefit of catheter ablation over antiarrhythmic drug therapy. 


\section{Cureus}

\section{Review}

The literature search (Table 1) was performed on the PubMed database using regular keywords. Studies were then filtered based on the following inclusion and exclusion criteria.

Inclusion Criteria:

1) Studies on human subjects written in English

2) Studies and articles published between the years 2000-2020

3) Full text available

4) Study subjects > 18 years old with atrial fibrillation

Exclusion Criteria:

1) Case-reports, case-series, systematic Reviews and meta-analyses

2) Articles irrelevant to the study objective

\begin{tabular}{|l|l|}
\hline Search buildup & Total Results \\
\hline Regular keywords- Atrial Fibrillation Catheter ablation mortality and stroke risk & 286 \\
\hline Inclusion Criteria & 284 \\
Published between $2000-2020$ & 270 \\
English language & 232 \\
Human Species & 224 \\
Full-text articles &
\end{tabular}

TABLE 1: Cumulative search results before and after applying the inclusion criteria.

After applying the inclusion criteria, search results (224 in total) were then manually reviewed to apply exclusion criteria, yielding 32 relevant articles that did not include case reports, case series, systematic reviews, and meta-analyses. Of the 32 articles, 16 were observational studies (mostly retrospective cohort), five were review articles, and 11 were randomized controlled trials. In addition, the American Heart Association (AHA)/American College of Cardiology (ACC) 2014 and 2019 guidelines were also reviewed to shed light on current treatment guidelines. Total study subjects of clinical trials were 5,542 compared to 98,445 patients who were enrolled in observational studies. Twenty-seven of the 32 chosen articles have been published within the last six years (84.375\%). The review encompasses catheter ablation in AF patients with and without heart failure (HF). Figure 1 summarizes the literature search process. 


\section{Cureus}

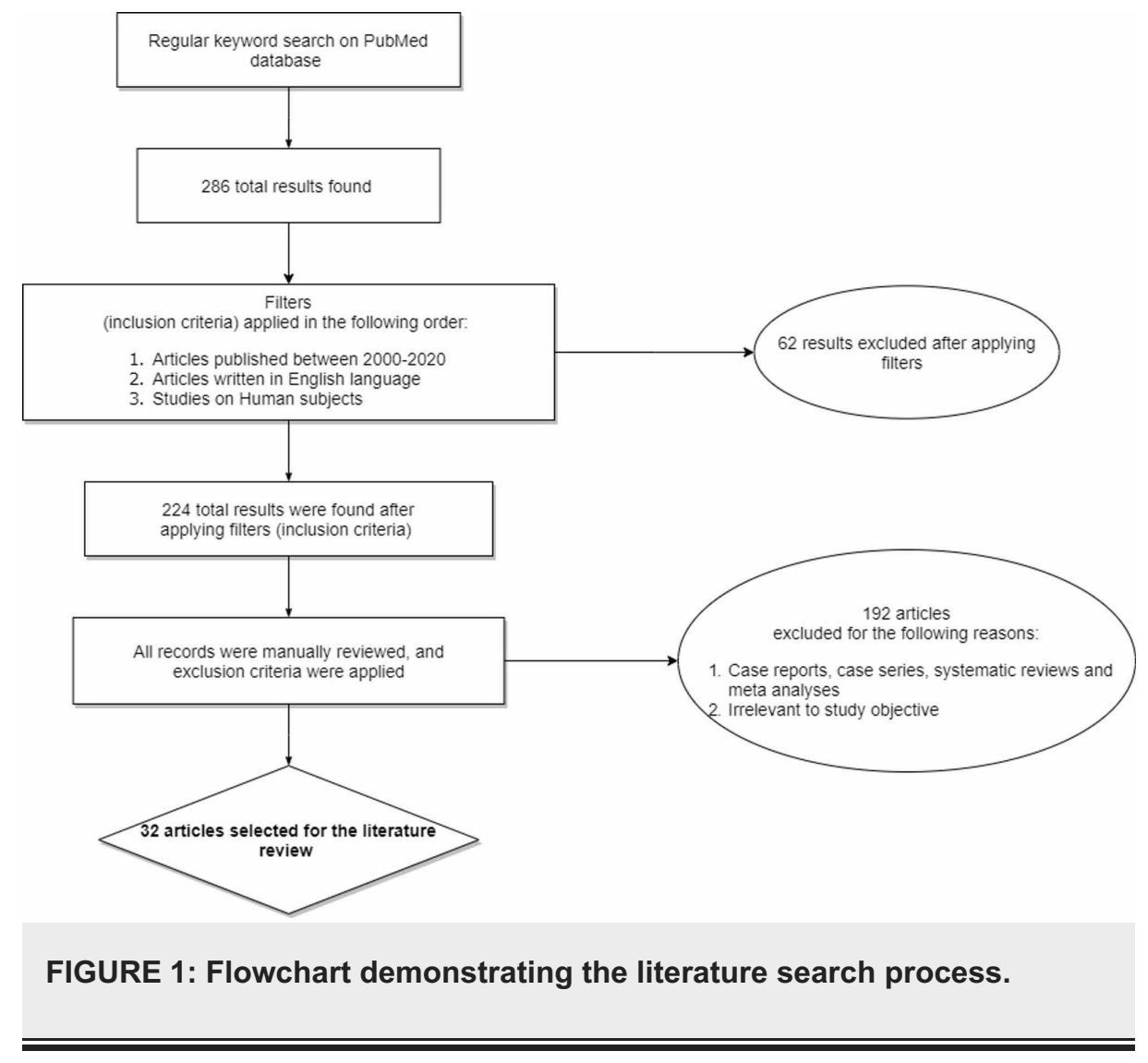

In the analysis of selected articles for the presented literature, we found sufficient evidence of the long-term benefit of catheter ablation in specific sub-populations of AF patients. However, evidence on whether catheter ablation reduces mortality and stroke risk in all patients with atrial fibrillation is still lacking. Articles reviewed specifically point to mortality benefit in patients with AF and HF [10-12], along with stroke risk reduction in patients with AF and high $\mathrm{CHA}_{2} \mathrm{DS}_{2}$-VASc score ( $\geqslant 2$ ) [13-15]. Multiple studies have also highlighted that maintaining sinus rhythm was the most important factor in predicting stroke-free survival and lower mortality [15-17]. Furthermore, besides the current consensus of preserving catheter ablation for symptomatic patients with drug-refractory atrial fibrillation [18], there is sufficient evidence that catheter ablation for patients with paroxysmal $\mathrm{AF}$ is highly effective in curtailing progression to persistent AF [19] and achieves better results of sinus rhythm maintenance [20]. Observational studies showing a mortality benefit with catheter ablation are summarized in Table 2 . 


\section{Cureus}

\begin{tabular}{|c|c|c|c|}
\hline $\begin{array}{l}\text { Author } \\
\text { Name/ } \\
\text { Year of } \\
\text { publication }\end{array}$ & Study Design & $\begin{array}{l}\text { Study } \\
\text { Subjects }\end{array}$ & Main findings \\
\hline $\begin{array}{l}\text { Arai et al., } \\
2019 \text { [21] }\end{array}$ & $\begin{array}{l}\text { Propensity- } \\
\text { matched } \\
\text { retrospective } \\
\text { observational } \\
\text { study }\end{array}$ & $\begin{array}{l}872 \text { patients } \\
\text { from Tokyo } \\
\text { registry data }\end{array}$ & $\begin{array}{l}\text { Significantly lower rate of all-cause death in the ablation group compared to the non-ablation } \\
\text { group (HR= } 0.37,95 \% \text { Confidence Interval: } 0.12-0.93, p=0.041 \text { ) }\end{array}$ \\
\hline $\begin{array}{l}\text { Srivatsa et } \\
\text { al., } 2018 \\
{[22]}\end{array}$ & $\begin{array}{l}\text { Propensity- } \\
\text { matched } \\
\text { retrospective } \\
\text { observational } \\
\text { study }\end{array}$ & $\begin{array}{l}8,338 \text { multi- } \\
\text { ethnic } \\
\text { patients in } \\
\text { California }\end{array}$ & $\begin{array}{l}\text { Lower } 30 \text {-day to } 5 \text {-year mortality of } 0.9 \% \text { (person-years) in the ablation group vs } 2 \% \text { in the no- } \\
\text { ablation control group; HR=0.57 ( } 95 \% \text { Confidence Interval: } 0.43-0.74, p<0.0001 \text { ) }\end{array}$ \\
\hline $\begin{array}{l}\text { Jarman et } \\
\text { al., } 2018 \\
\text { [23] }\end{array}$ & $\begin{array}{l}\text { Propensity- } \\
\text { matched } \\
\text { retrospective } \\
\text { cohort study }\end{array}$ & $\begin{array}{l}1,116 \text { patients } \\
\text { in England }\end{array}$ & $\begin{array}{l}50 \% \text { lower risk of mortality in the ablation group compared to the anti-arrhythmic drug group }(p= \\
0.0082) \text { over } 3 \text { years of follow-up. }\end{array}$ \\
\hline $\begin{array}{l}\text { Friberg et } \\
\text { al., } 2016 \\
{[14]}\end{array}$ & $\begin{array}{l}\text { Propensity- } \\
\text { matched } \\
\text { retrospective } \\
\text { observational } \\
\text { study }\end{array}$ & $\begin{array}{l}\text { 4,992 patients } \\
\text { from Swedish } \\
\text { health } \\
\text { registries }\end{array}$ & $\begin{array}{l}\text { The annual mortality rate was } 0.77 \% \text { in the ablated group compared to } 1.62 \% \text { in the non-ablated } \\
\text { group ( }<<0.001) \text {, with cardio-vascular deaths being twice as common in the non-ablated group } \\
\text { compared to the ablated group. }\end{array}$ \\
\hline $\begin{array}{l}\text { Nademanee } \\
\text { et al., } 2015 \\
{[17]}\end{array}$ & $\begin{array}{l}\text { Retrospective } \\
\text { cohort study }\end{array}$ & $\begin{array}{l}324 \text { elderly } \\
\text { patients ( } \geq 75 \\
\text { years old) with } \\
\text { symptomatic } \\
\text { AF }\end{array}$ & $\begin{array}{l}\text { Significantly lower } 5 \text {-year mortality in ablation patients who successfully maintained normal sinus } \\
\text { rhythm compared to ablation patients who failed to maintain sinus rhythm and patients assigned } \\
\text { to medical rate control }(87 \%, 52 \% \text {, and } 42 \% \text { respectively, } p<0.0001) \text {. Catheter ablation was more } \\
\text { successful in reducing AF burden and maintaining normal sinus rhythm, which was an } \\
\text { independent factor of better survival. }\end{array}$ \\
\hline $\begin{array}{l}\text { Lin et al., } \\
2013[15]\end{array}$ & $\begin{array}{l}\text { Propensity } \\
\text { matched } \\
\text { retrospective } \\
\text { observational } \\
\text { study }\end{array}$ & $\begin{array}{l}348 \text { patients } \\
\text { with } \\
\text { symptomatic } \\
\mathrm{AF} \text { and } \\
\mathrm{CHA}_{2} \mathrm{DS}_{2-} \\
\text { VASc score } \geq \\
1\end{array}$ & $\begin{array}{l}\text { Lower rate of all-cause mortality and cardiovascular deaths in ablated group vs non-ablated } \\
\text { group }(2.95 \% \text { vs. } 0.74 \% \text { per year; } p<0.01 \text { and } 1.77 \% \text { vs. } 0 \% \text { per year; } p=0.001 \text { respectively) } \\
\text { over a mean follow-up period of } 47 \pm 23 \text { months. }\end{array}$ \\
\hline $\begin{array}{l}\text { Bunch et } \\
\text { al., } 2011 \\
{[24]}\end{array}$ & $\begin{array}{l}\text { Prospective } \\
\text { cohort study }\end{array}$ & $\begin{array}{l}37,908 \\
\text { predominantly } \\
\text { white patients }\end{array}$ & $\begin{array}{l}\text { 5-year mortality rates for ablated AF patients was significantly lower than non-ablated AF patients } \\
\text { and similar to non-AF patients }(7.6 \%, 27.9 \% \text {. and } 11.4 \% \text { respectively })\end{array}$ \\
\hline
\end{tabular}

\section{TABLE 2: Studies that demonstrate the long-term mortality benefit of catheter ablation.}

HR: Hazard Ratio, AF: atrial fibrillation

Most of the studies have attributed possible long-term mortality benefit of catheter ablation to the higher efficacy in restoring sinus rhythm and reducing AF recurrence despite often required repeat procedures $[5$, $17,20,25]$. On the other hand, some studies have shown no mortality benefit of catheter ablation over medical therapy, including the long-awaited, large, randomized, controlled Catheter Ablation Versus Antiarrhythmic Drug Therapy for Atrial Fibrillation (CABANA) trial. In this multi-center, open-label study, 1108 patients were assigned to receive catheter ablation against 1096 matched controls receiving medical therapy. The main findings of the study were that over a median follow-up period of 48.5 months; there was no significant difference in all-cause mortality (5.2\% in ablation group vs. $6.1 \%$ in drug therapy group, hazard ratio [HR]: 0.85 [95\% CI, 0.60-1.21]; $\mathrm{p}=0.38$ ) between both groups using intention-to-treat analysis despite ablation therapy showing better results in reducing AF recurrence (49.9\% in ablation group vs. $69.5 \%$ in drug therapy group, HR: 0.52 [95\% CI, 0.45-0.60]; $\mathrm{p}<.001$ ). However, treatment assignment sensitivity analysis showed that there is a benefit for ablation over medical therapy if patients assigned to ablative therapy did receive ablation. Moreover, there was a $27 \%$ crossover from the medical therapy group to the ablation group, which highlights the relative inefficacy and hazardous side effect profile of antiarrhythmic medications. In a recent, large 2019 propensity-matched observational study it was also 
concluded that there was no difference in mortality and cardiovascular deaths between ablated patients and medically treated patients [26]. The study follow-up period, however, was only one year, which may indicate that the mortality benefits of ablation therapy are not seen before $\geqslant$ two years of post-ablation follow-up.

$\mathrm{AF}$ and heart failure are frequently co-existent conditions. It is often difficult for clinicians to determine the 'chicken-egg' relationship between the two as both conditions share similar risk factors and may lead to each other. Atrial fibrillation compromises left ventricular function due to loss of atrial systole and may cause tachycardia-mediated cardiomyopathy [27], while heart failure may induce atrial remodeling and fibrosis, which promotes AF. Multiple studies (Table 3), including randomized controlled trials, have demonstrated significant mortality benefit, improved left ventricular function, and quality of life with catheter ablation in patients with AF and comorbid heart failure.

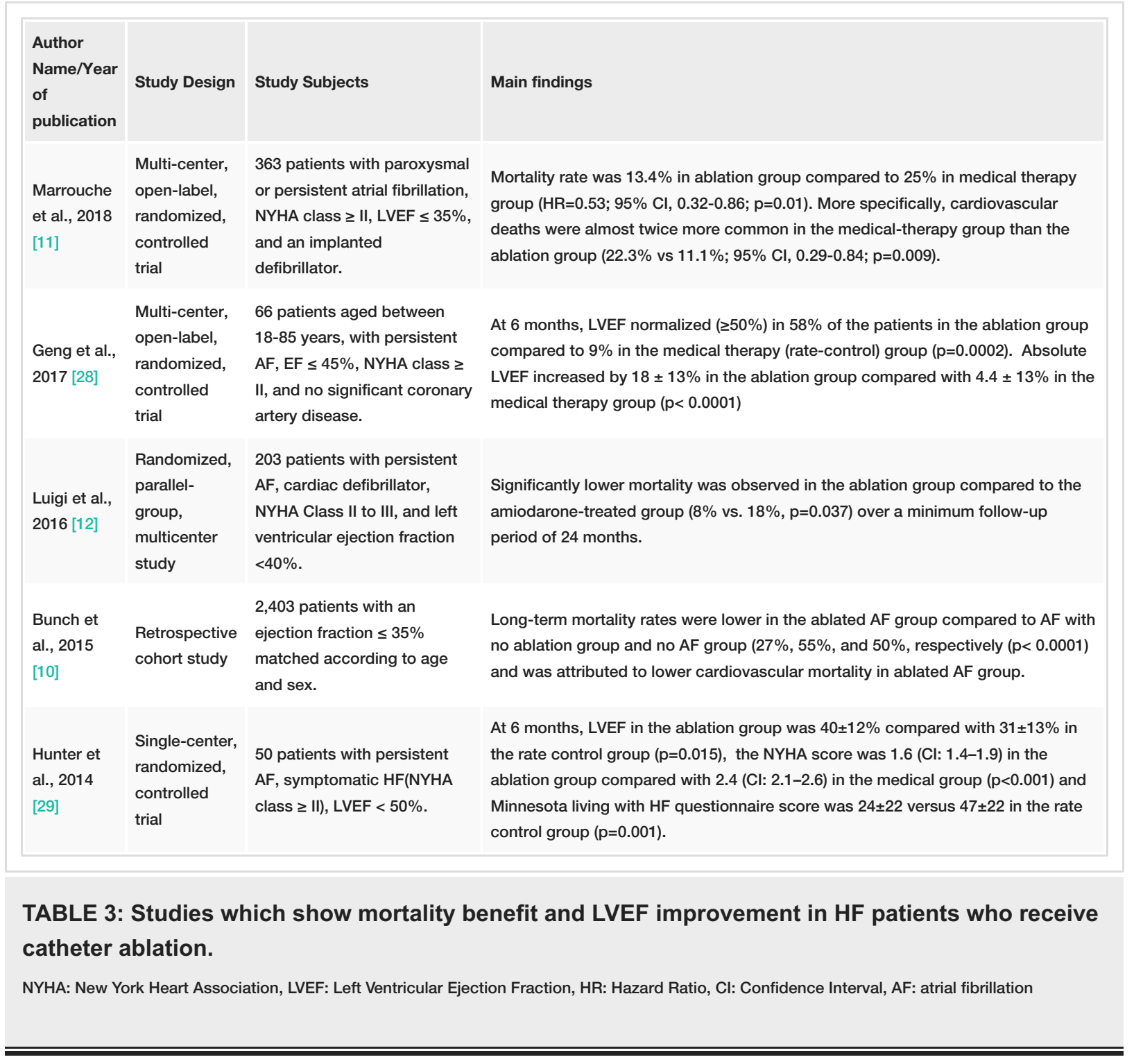

In contrast to the trials mentioned above, the Atrial Fibrillation Management in Congestive Heart Failure With Ablation (AMICA) trial, a randomized controlled trial in 2019, failed to show a significant benefit of ablation therapy over medical therapy [30]. Unlike other trials, medical therapy improved left ventricular ejection fraction (LVEF) in patients with persistent AF and left ventricular systolic dysfunction by a magnitude not deemed statistically different from that of ablation therapy at one year (7.3\% [CI: 4.3\%10.3\%] and 8.8\% [CI: 5.8\%-11.9\%], respectively). The study authors explained that the limited benefit of catheter ablation in their study subjects was because they were generally sicker and with more advanced HF compared with the patient population in other studies (particularly the Catheter Ablation vs. Standard Conventional Treatment in Patients With LV Dysfunction and AF [CASTLE-AF] trial). They concluded that ablation therapy might have limited benefit over medical treatment in improving left ventricular function and quality of life in patients with seriously advanced HF despite achieving lower AF burden. Overall, the evidence pointing towards the mortality benefit of ablation therapy in AF patients with comorbid systolic heart failure is quite compelling. In fact, the 2019 ACC/AHA guidelines for AF management mention that it is reasonable to consider ablation therapy in AF patients with reduced LVEF (Class of Recommendation: IIb, 
Regarding the long-term risk of stroke, in 2017, a large study in Israel investigated the long-term outcomes of ablation therapy in 969 patients against a propensity score-matched cohort of 3772 non-ablated patients (ratio of 1: \$4). At baseline, most of the study subjects in both groups were at high risk for stroke (mean $\mathrm{CHA}_{2} \mathrm{DS}_{2}$-VASc score: $3.6 \pm 2.0$ ). However, after long-term follow-up, the rates of transient ischemic attack (TIA), stroke, and mortality were significantly lower among the ablation group compared with the non-ablation group [13]. Other previously discussed observational studies have reported similar findings among patients at high risk for stroke [14-16] Furthermore, in patients with a previous history of cerebrovascular accident, it was found that the risk of a subsequent stroke in ablated AF patients was similar to that of non-AF patients and significantly lower than that of non-ablated AF patients [32]. Despite the apparent benefit, the role of oral anticoagulants (OACs) in stroke prevention should not be overlooked in ablated patients. In a large recent study of US national registry data, it was found that in about one out of four patients treated with catheter ablation, OACs were discontinued despite having a high risk of stroke $\left(\mathrm{CHA}_{2} \mathrm{DS}_{2}-\mathrm{VASc} \geqslant 2\right)[26]$. A recent propensity-matched retrospective cohort study in Japan investigated the long-term risk of stroke in ablated patients with non-ablated patients. It was found that there was no difference in the incidence of stroke between ablated and non-ablated patients over a follow-up period of $28.0 \pm 17.1$ months despite significantly lower rates of mortality and cardiovascular deaths in the ablated group. Interestingly, OACs were discontinued in 230 out of 512 ablated patients, among which $25 \%$ had a $\mathrm{CHA}_{2} \mathrm{DS}_{2}$-VASc score $>3$ [21]. Thus, it remains clear that ablation therapy should not be used for the sake of discontinuing OACs in patients at high risk of stroke, but instead both therapies should be combined for better mitigation of stroke risk.

Some studies suggest a unique advantage for ablation therapy in patients with paroxysmal AF. In these patients, it has been found that catheter ablation limits the progression to persistent AF by a rate of $<3 \%$ over two to five years compared to a rate of $11-26 \%$ over one year observed in medically treated patients [19]. Furthermore, in another study, it was found that patients with paroxysmal AF were more likely to maintain sinus rhythm after ablation therapy compared to those with persistent AF (proportion of time in sinus rhythm: $0.74 \pm 0.34$ vs. $0.52 \pm 0.38$; $\mathrm{p}<0.0001$ ) [20]. The mortality rate in this study was significantly higher over 10 years in patients with persistent $\mathrm{AF}$ than those with paroxysmal AF and similar to other studies, maintenance of sinus rhythm was associated with a substantially lower risk of cardiac mortality (HR: 0.41; 95\% CI:0.20-0.84, $\mathrm{p}=0.015$ ). Predictors of mortality were age, comorbid diseases (coronary artery disease, hypertension, diabetes mellitus, and obstructive sleep apnea), lower LVEF, and increased left atrium (LA) size.

Discussing long-term outcomes of a procedure may seem futile if we do not consider the different modes of carrying it out and whether one method is more successful. In 2019, a randomized controlled trial on 346 patients with drug-refractory paroxysmal AF compared radiofrequency ablation with 2-minute cryoballoon ablation and 4-minute cryoballoon ablation. All patients were subjected to continuous rhythm monitoring using an implantable loop recorder to test the primary outcome of freedom from arrhythmia recurrence at one year. The efficacy of the three procedures at one year was not statistically different $(79.1 \%$ in radiofrequency group vs. $78.2 \%$ in 4 -minute cryoballoon ablation group, and $73.3 \%$ in the 2 -minute cryoballoon ablation; $\mathrm{p}=0.26)$.

In general, catheter ablation is considered a relatively safe procedure with a low risk of complications. Results from the California Study of Ablation for Atrial Fibrillation (CAABL-AF) study that included 4169 ablated patients showed a $0.001 \%$ risk of mortality and $0.003 \%$ risk of stroke within 30 days of the procedure [22]. Another propensity-matched retrospective study compared the outcome of stroke in 12,177 ablated patients to an equal group of cardioversion patients and found out that the initial risk of stroke within 30 days of the procedure was higher in the ablation group (RR: 1.53; $\mathrm{P}=0.05$ ) [33]. In contrast, a 2014 randomized controlled trial investigated the periprocedural (within 48 hours of ablation) risk of stroke in patients who discontinued warfarin before the procedure (bridged with heparin) versus patients who were maintained on warfarin and found that uninterrupted warfarin reduced the risk of thromboembolic events by $95 \%$ [34]. This finding surely carries a lot of weight in reducing peri-ablation stroke risk and shall modify the current standards of practice, especially if complemented by other similar trials.

The main limitation of this study is that we did not include data from systematic reviews and meta-analyses. However, most of the studies reviewed were recent large observational studies or randomized controlled trials to shed light on the latest state of knowledge.

\section{Conclusions}

Several observational studies have found that catheter ablation for atrial fibrillation reduces long-term risk of stroke and mortality compared to medical therapy. Randomized controlled trials have mainly demonstrated this benefit in the HF population but not the non-HF population. Reduction in stroke risk was most significant among patients with a high $\mathrm{CHA}_{2} \mathrm{DS}_{2}$-VASc score $(\geqslant 2)$ and those with a previous history of stroke, provided anti-coagulant therapy is not discontinued. The most important factor implicated in the reduction of stroke and mortality is maintenance of sinus rhythm, which is better achieved by ablation therapy compared to anti-arrhythmic medications. Catheter ablation may offer a special advantage in 
patients with paroxysmal AF since it has been shown to better limit its progression to persistent AF than anti-arrhythmic medication. Furthermore, patients with paroxysmal AF who undergo catheter ablation tend to maintain sinus rhythm for a larger proportion of time than persistent AF patients. Catheter ablation is considered a relatively safe procedure with minimal periprocedural stroke and mortality risk. Periprocedural stroke risk is significantly reduced when warfarin therapy is maintained as opposed to warfarin discontinuation and bridging with heparin before the procedure. Large randomized controlled trials similar to the CABANA trial are still needed to confirm the long-term benefit of catheter ablation over medical therapy, as shown by observational studies as findings of the CABANA trial have been inconclusive and showed no significant superiority.

\section{Additional Information \\ Disclosures}

Conflicts of interest: In compliance with the ICMJE uniform disclosure form, all authors declare the following: Payment/services info: All authors have declared that no financial support was received from any organization for the submitted work. Financial relationships: All authors have declared that they have no financial relationships at present or within the previous three years with any organizations that might have an interest in the submitted work. Other relationships: All authors have declared that there are no other relationships or activities that could appear to have influenced the submitted work.

\section{References}

1. Lippi G, Sanchis-Gomar F, Cervellin G: Global epidemiology of atrial fibrillation: an increasing epidemic and public health challenge [PREPRINT]. Int J Stroke. 2020, 10.1177/1747493019897870

2. January CT, Wann LS, Alpert JS, et al.: 2014 AHA/ACC/HRS guideline for the management of patients with atrial fibrillation: a report of the American College of Cardiology/American Heart Association Task Force on practice guidelines and the heart rhythm society. J Am Coll Cardiol. 2014, 64:e1-e76. 10.1016/j.jacc.2014.03.022

3. Wolf PA, Abbott RD, Kannel WB: Atrial fibrillation as an independent risk factor for stroke: the Framingham Study. Stroke. 1991, 22:983-988. 10.1161/01.STR.22.8.983

4. Wyse DG, Waldo AL, DiMarco JP, et al.: A comparison of rate control and rhythm control in patients with atrial fibrillation. N Engl J Med. 2002, 347:1825-1833. 10.1056/NEJMoa021328

5. Wilber DJ, Pappone C, Neuzil P, et al.: Comparison of antiarrhythmic drug therapy and radiofrequency catheter ablation in patients with paroxysmal atrial fibrillation: a randomized controlled trial. JAMA. 2010, 303:333-340. 10.1001/jama.2009.2029

6. Morillo CA, Verma A, Connolly SJ, et al.: Radiofrequency ablation vs antiarrhythmic drugs as first-line treatment of paroxysmal atrial fibrillation (Raaft-2): a randomized trial. JAMA. 2014, 311:692-700. 10.1001/jama.2014.467

7. Pierre J, Cauchemez B, Macle L, et al.: Catheter ablation versus antiarrhythmic drugs for atrial fibrillation . Circulation. 2008, 118:2498-2505. 10.1161/CIRCULATIONAHA.108.772582

8. Blomström-Lundqvist C, Gizurarson S, Schwieler J, et al.: Effect of catheter ablation vs antiarrhythmic medication on quality of life in patients with atrial fibrillation: the CAPTAF randomized clinical trial. JAMA. 2019, 321:1059-1068. 10.1001/jama.2019.0335

9. Kalman M, Sanders P, Rosso R, Calkins H: Should we perform catheter ablation for asymptomatic atrial fibrillation?. Circulation. 2017, 136:490-499. 10.1161/CIRCULATIONAHA.116.024926

10. Bunch TJ, May HT, Bair TL, et al.: Five-year outcomes of catheter ablation in patients with atrial fibrillation and left ventricular systolic dysfunction: catheter ablation and long-term outcomes. J Cardiovasc Electrophysiol. 2015, 26:363-370. 10.1111/jce.12602

11. Marrouche NF, Brachmann J, Andresen D, et al.: Catheter ablation for atrial fibrillation with heart failure . N Engl J Med. 2018, 378:417-427. 10.1056/NEJMoa1707855

12. Luigi DB, Mohanty P, Mohanty S, et al.: Ablation versus amiodarone for treatment of persistent atrial fibrillation in patients with congestive heart failure and an implanted device. Circulation. 2016, 133:16371644. 10.1161/CIRCULATIONAHA.115.019406

13. Saliba W, Schliamser JE, Lavi I, Barnett-Griness O, Gronich N, Rennert G: Catheter ablation of atrial fibrillation is associated with reduced risk of stroke and mortality: a propensity score-matched analysis. Heart Rhythm. 2017, 14:635-642. 10.1016/.hrthm.2017.02.001

14. Friberg L, Tabrizi F, Englund A: Catheter ablation for atrial fibrillation is associated with lower incidence of stroke and death: data from Swedish health registries. Eur Heart J. 2016, 37:2478-2487. 10.1093/eurheartj/ehw087

15. Lin Y, Chao T, Tsao H, et al.: Successful catheter ablation reduces the risk of cardiovascular events in atrial fibrillation patients with CHA2DS2-VASc risk score of 1 and higher. EP Europace. 2013, 15:676-684. 10.1093/europace/eus336

16. Hunter RJ, McCready J, Diab I, et al.: Maintenance of sinus rhythm with an ablation strategy in patients with atrial fibrillation is associated with a lower risk of stroke and death. Heart. 2012, 98:48-53. 10.1136/heartjnl-2011-300720

17. Nademanee K, Amnueypol M, Lee F, et al.: Benefits and risks of catheter ablation in elderly patients with atrial fibrillation. Heart Rhythm. 2015, 12:44-51. 10.1016/j.hrthm.2014.09.049

18. Eyre-Brook SN, Rajappan K: Catheter ablation for atrial fibrillation: who, why and does it work? . Postgrad Med J. 2012, 88:604-611. 10.1136/postgradmedj-2012-130896

19. Latchamsetty R, Morady F: Long-term benefits following catheter ablation of atrial fibrillation . Circ J. 2013, 77:1091-1096. 10.1253/circj.CJ-13-0298

20. Ghanbari H, Başer K, Jongnarangsin K, et al.: Mortality and cerebrovascular events after radiofrequency 
catheter ablation of atrial fibrillation. Heart Rhythm. 2014, 11:1503-1511. 10.1016/j.hrthm.2014.05.003

21. Arai M, Okumur Y, Nagashima K, et al.: Adverse clinical events during long-term follow-up after catheter ablation of atrial fibrillation: comparison to a non-ablation patient group. Int Heart J. 2019, 60:812-821. 10.1536/ihj.18-517

22. Srivatsa UN, Danielsen B, Amsterdam EA, et al.: CAABL-AF (California Study of Ablation for Atrial Fibrillation). Circ Arrhythm Electrophysiol. 2018, 11:e005739. 10.1161/CIRCEP.117.005739

23. Jarman JW, Hussain W, Wong T, et al.: Resource use and clinical outcomes in patients with atrial fibrillation with ablation versus antiarrhythmic drug treatment. BMC Cardiovasc Disord. 2018, 18:211. 10.1186/s12872018-0946-6

24. Bunch TJ, Crandall BG, Weiss JP, et al.: Patients treated with catheter ablation for atrial fibrillation have long-term rates of death, stroke, and dementia similar to patients without atrial fibrillation. J Cardiovasc Electrophysiol. 2011, 22:839-845. 10.1111/j.1540-8167.2011.02035.x

25. Bertaglia E, Senatore G, De Michieli L, et al.: Twelve-year follow-up of catheter ablation for atrial fibrillation: a prospective, multicenter, randomized study. Heart Rhythm. 2017, 14:486-492. 10.1016/j.hrthm.2016.12.023

26. Freeman JV, Shrader P, Pieper KS, et al.: Outcomes and anticoagulation use after catheter ablation for atrial fibrillation. Circ Arrhythm Electrophysiol. 2019, 12:e007612. 10.1161/CIRCEP.119.007612

27. Ling LH, Kistler PM, Kalman JM, Schilling RJ, Hunter RJ: Comorbidity of atrial fibrillation and heart failure . Nat Rev Cardiol. 2016, 13:131-147. 10.1038/nrcardio.2015.191

28. Geng J, Zhang Y, Yanhan P, et al.: Catheter ablation versus rate control in patients with atrial fibrillation and heart failure. Medicine (Baltimore). 2017, 96:e9179. 10.1097/MD.0000000000009179

29. Hunter RJ, Berriman TJ, Diab I, et al.: A randomized controlled trial of catheter ablation versus medical treatment of atrial fibrillation in heart failure (the CAMTAF trial). Circ Arrhythm Electrophysiol. 2014, 7:3138. 10.1161/CIRCEP.113.000806

30. Kuck KH, Merkely B, Zahn R, et al.: Catheter ablation versus best medical therapy in patients with persistent atrial fibrillation and congestive heart failure: the randomized AMICA trial. Circ Arrhythm Electrophysiol. 2019, 12:e007731. 10.1161/CIRCEP.119.007731

31. January CT, Wann LS, Calkins H, et al.: 2019 AHA/ACC/HRS focused update of the 2014 AHA/ACC/HRS guideline for the management of patients with atrial fibrillation: a report of the American College of Cardiology/American Heart Association Task Force on Clinical Practice Guidelines and the Heart Rhythm Society in collaboration with the Society of Thoracic Surgeons. Circulation. 2019, 140:e125-e151. 10.1161/CIR.0000000000000665

32. Bunch TJ, May HT, Bair TL, et al.: Five-year impact of catheter ablation for atrial fibrillation in patients with a prior history of stroke. J Cardiovasc Electrophysiol. 2018, 29:221-226. 10.1111/jce.13390

33. Noseworthy PA, Kapa S, Deshmukh AJ, et al.: Risk of stroke after catheter ablation versus cardioversion for atrial fibrillation: a propensity-matched study of 24,244 patients. Heart Rhythm. 2015, 12:1154-1161. 10.1016/j.hrthm.2015.02.020

34. Di Biase L, Burkhardt JD, Santangeli P, et al.: Periprocedural stroke and bleeding complications in patients undergoing catheter ablation of atrial fibrillation with different anticoagulation management. Circulation. 2014, 129:2638-2644. 10.1161/CIRCULATIONAHA.113.006426 